AFMRD from the assodiation Association of Family Medicine of Family Medicine Residency Directors Residency Directors

Ann Fam Med 2020;18:91-92. https://doi.org/10.1370/afm.2510.

\section{ON COMING HOME AFTER THE FIRES}

When I first became the Program Director of the Sutter Santa Rosa Family Medicine Residency in June of 2017, I thought I had my hands full. Learning the ropes of running a community-based residency program, continuing to be a teacher, and trying to maintain my small outpatient panel seemed like an overfull plate at the time. I had no idea of the challenges that lay only a few months ahead of us, when our community was struck by the devastating Tubbs fire, a catastrophe that left our program —and hundreds of our patientswithout a home.

Nearly 2 years after those fateful fires, a timespan that feels both like an eternity and like the blink of an eye, we moved back into our rebuilt Vista Health Center in August 2019. Once again, we have our residency office, continuity clinic, and teaching space within the same building and are close to our sponsoring hospital On the tails of this momentous homecoming, and just as I was writing this article, Sonoma County was ironically stuck by another megafire, this time called the Kincaid Fire. Like the previous fire, the Kincaid fire brought community-wide evacuations and power outages, 2 hospital closures, and evacuation shelters. Being called upon to respond to disaster again has highlighted some ways that our program has changed and a few important lessons about disaster that are worth sharing with the larger family medicine community.

\section{Family Physicians are Uniquely Qualified to Support the Medical Needs of the Community During Disaster}

The skillset of the family doctor is precisely what is needed when providing medical care for communities that are displaced and when the medical system has been impacted by a disaster. We may not have known it when the Tubbs Fire hit, but as family physicians we already possessed the skills that were needed to respond to the community. Our experience in both rounds of fire response showed us that much of the care that displaced people need is identical to what nondisplaced people need: reassurance, treatment of chronic disease, empathy, minor acute care, and triage to a higher level of care. Who better than family physicians to fill this role?

\section{Programs Can Take Steps Now to Build Resilience and Preparedness to Face Adversity Into the Fabric of the Training Curriculum}

Like all first responders, residents who are experiencing disaster in the midst of training while providing care for the wounded and displaced suffer unique forms of distress. In addition, residents may worry about the wellbeing of their program and potential negative impacts on their training and future career. In our program, residents and faculty have regular time to meet with their classmates or fellow faculty facilitated by a psychologist. Protected time for bonding, sharing the stress of training, feeling heard by colleagues and having opportunities to listen and support others have always been important in our residency, but they became critical for cohesion and recovery when disaster struck here in Santa Rosa.

\section{People, Residency Programs, and Communities Experience and Recover From Disaster Differently}

Like a multigenerational family facing disaster, in Santa Rosa we were each affected differently by the Tubbs fire. Factors such as the roles we played, how much agency we had, the amount of fear we personally experienced and how much damage was done in our personal and professional lives when the fires were extinguished were all filtered through the context of our developmental phase and life experience. There is no one-size-fits-all response to grieving or healing. For residents in our program, there is no doubt that this has been a seminal event not only in their training but in their lives. My deepest hope is that their experience in joining their residency and community colleagues in the vanguard of the disaster response, caring for the community as it recovered and experiencing our own renewal will be what stays with them after they leave us. With any luck, it has built their pride in our specialty and confidence in their own skills to respond to, and even lead, a response to disaster in the future.

\section{People, Programs, and Communities Can Become More Proficient in Responding to Disaster Through Exposure}

When the Kincaid Fire hit a few weeks ago, our leadership team was able to flip into incident command mode almost effortlessly. Our county was able to plan preventive, coordinated mass evacuations allowing our hospital and local residents to evacuate in a more controlled way. With this fire we were able to coordinate care in the shelters within 24 hours instead of the better part of a week. Additionally, we were able to think through the options that we offered residents and faculty so they could titrate their level of engagement 
to their own level of personal threat, family needs, and evacuation status. Happily, our town and program fared much better in the Kincaid Fire and it offered us an opportunity to put our disaster response expertise to use and increased our confidence for next time.

When I think ahead to a time when all the residents who have experienced the fires have graduated, and some or all the faculty who were here have retired, I know that this period will be stand out in our program's history. We hope we will never again face such trials and our community and program will continue on the path to recovery. But if the fires do continue, our experience these past 2 years has showed me that our specialty and our program hold the knowledge we need to respond, recover, and survive.

I invited Dr Sara Martin, MD, a current PGY-3 in our program to share a few reflections about how the Tubbs and Kincaid Fires have shaped her training. Dr Martin and her classmates were just a few months into residency when the Tubbs Fire hit.

TS: Now that we are settling in to our old bealth center again, where do the fires figure into your day to day life?

SM: Everyone assumed the Tubbs Fire was a once-ina-lifetime event, that it would never happen again. A year later the Camp Fire, in a nearby county, made the Tubbs Fire look small. Another year later, we faced the largest evacuation in California history as the Kincaid fire threatened our town. Our hospital has been evacuated twice in the 3 years of my residency training. With all of that, there's a sense of uncertainty. A question of whether this is the new normal. I wonder how residency would have felt without these natural disasters, and think about how my training would have been different. In what ways am I less (or more) of a doctor because of these disasters?

There are obvious ways in which the fires have impacted me, implications that are already apparent. There's the fact that I now have an earthquake plan, a flood plan, and a fire plan for my family. There's the fact that as I look at jobs, I wonder how their community would come together in a disaster, and what their plan is for evacuating their hospital. How do you ask that at a job interview?

TS: How did your experience of our program responding to the fires in our community shape your view of Family Medicine?

SM: I can wholeheartedly tell people that even with the experience of the fires, I would choose my residency training experience again. The reason is simple: it taught me what it means to truly be a family physician. The fire showed me-in a way that I couldn't have seen otherwise - that I was part of a family that encompassed a whole community, and that a whole community encompassed me, as a learner, as a person, and as a physician.

The sense of what it meant to be a family physician was embodied by the outpouring of support from our community. From the physicians at our sister clinics who voluntarily stopped seeing their patients so we had the physical space to continue our training; to the medical assistants who made do with cramped space and standing computers in tight hallways; to the patients who would celebrate "finding us" as we moved from clinic to clinic. No one stopped focusing on the reason we were there: the community.

I'll never forget when a patient welcomed me "home" to our original clinic when it reopened 2 years after the fire. The fires weren't easy, but the community response-and our small role in it as family physicians-was inspiring.

Tara Scott, MD, and Sara Martin, MD 